\title{
EDUCAÇÃO, GÊNERO E POLÍTICA: DEBATES CONTEMPORÂNEOS
}

\section{EDUCATION, GENDER AND POLICY: CONTEMPORARY DEBATES}

\section{EDUCACIÓN, GÉNERO Y POLÍTICAS: DEBATES CONTEMPORÁNEOS}

Thiago Romeu de Souza ${ }^{1}$

Heloísa Costa Rigon ${ }^{2}$

1. Doutor em Geografia pela Universidade Federal de Pernambuco (UFPE). Professor Adjunto da Unidade Acadêmica de Geografia da Universidade Federal de Campina Grande (UFCG). E-mail: thiago_romeu2000@yahoo.com.br

2. Mestra em Literatura e Interculturalidade pela Universidade Estadual da Paraíba (UEPB). Professora Substituta no Departamento de Letras e Artes (UEPB). E-mail: heloisarigon@gmail.com

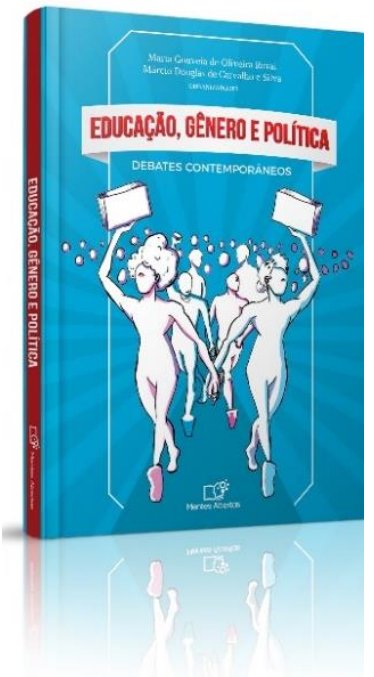

ROVAI, Marta Gouveia de Oliveira; SILVA, Márcio Douglas de Carvalho (Orgs.) Educação, Gênero e Política: debates contemporâneos. São Paulo: Mentes Abertas, 2020. 184 pp.

\section{https://mentesabertas.minhalojanouol.com.br/produto/318264/educacao-genero-e-politica}

Recebido em: 10/10/2020

Aprovado em: 14/11/2020

Grande parte do debate contemporâneo que permeia a teoria social envolve os temas que intitulam esta obra. As principais questões deste primeiro quarto de século passam, direta ou indiretamente, por um destes três temas, quando não os envolvem todos ao mesmo tempo. Educação, gênero e política são mais que temas da teoria social, são emblemas de instituições, consignias de ação social e pauta de manchetes de jornal. Estão no nosso cotidiano de modo tão peremptório que o alcance social é incomensurável, assim 
como seus desdobramentos no imaginário das sociedades tanto em termos pragmáticos quanto analíticos. Diante da evidente relevância dos temas, o livro em tela ambicionou apresentar debates contemporâneos que envolvem alguns elementos que interligam estes temas. Educação e Gênero "são os dois fios pelos quais as subjetividades, as identidades e as questões sociais vão sendo alinhavadas pelos diferentes autores", dizem os organizadores na página 11. Tarefa árdua e necessária para se compreender os intrincados interesses que formam a terceira categoria apresentada no título: aquela representada pela palavra "política".

No que se refere ao desafio de unir estes temas tão relevantes, tão comuns, mas tão complexos, os organizadores tiveram dificuldade em conectar de maneira clara o conjunto de textos de maneira harmônica e coerente. Certamente, os temas se articulam e a realidade não deixa dúvidas sobre este fato, mas os objetivos particulares dos textos parecem fugir de uma proposta comum. É bem verdade que a dimensão subjetiva, as esferas subalternas e a questão das identidades, por si só, realizam o nexo e todos os textos abordam, cada qual a sua maneira, estas questões, porém, não são suficientes para haver um direcionamento comum ao conjunto da obra. Evidentemente, política, gênero e educação são temas que de modo quase imediato se vinculam porque tocam diretamente nas estruturas de poder e no seu modus operandi e, neste sentido, os textos são pródigos de exemplos, todavia, não parecem buscar uma orientação comum.

Apesar desta ausência, há que se considerar a importante reunião de pesquisadores de lugares periféricos da produção de conhecimento no país. Este fato não pode ser caracterizado como algo menos relevante. A presença de pesquisadores do Rio Grande do Norte, do Piauí, do Amazonas, do Pará, interior de Minas Gerais e interior do Rio Grande do Sul demonstram o interesse dos organizadores em dar azo ao conhecimento produzido com rigor em pontos não centrais do país, ao passo que ilumina a trajetória de diversos sujeitos invisibilizados ao longo da formação da nossa população, nestes "lugares opacos", como diria Milton Santos, tão constitutivos de nossa identidade territorial. Ao mesmo tempo em que consolida a força das universidades (públicas, sobretudo) no diálogo entre centro e periferia, visto que os autores transitaram/transitam entre as diversas regiões do país na construção de sua formação e forjam aquilo que Boaventura Sousa Santos entre outros chamam de diálogos Sul-Sul, trocando experiências entre os saberes de pontos não hegemônicos do país.

No que se refere às trajetórias, este é, sem dúvida um ponto forte da proposta dos organizadores. Primeiro, porque capta como aspecto central para a análise historiográfica (e porque não dizer de toda a teoria social) os métodos da História Oral, que longe de ser uma metodologia acessória à História, tem se revelado um verdadeiro caminho para a compreensão das sociedades, uma vez que dá lugar de fala a quem nunca foi enxergado como sujeito de direitos, quanto mais com uma história válida. Segundo, porque permite que por esta apresentação de trajetórias de sujeitos e grupos se perceba o tão desejável nexo entre 
os textos. Mulheres trabalhadoras e/ou estigmatizadas, crianças que se alimentam na escola, antigos estudantes de uma escola num litoral afastado da capital, uma professora e seus alunos noutro litoral isolado, o que une estes sujeitos? Sem dúvida, suas trajetórias subalternas, não hegemônicas e periféricas que ora se apresentam não como interstício da epopeia de um povo, mas como a marca central deste povo, cujas trajetórias invisibilizadas são o que torna digna a existência desta nação, chamada por alcunha de Brasil, terra desta árvore homônima cujo labor da extração fez surgir o gentílico "brasileiro". O povo brasileiro, enredado nos singelos exemplos apresentados no livro, ganham não só visibilidades como dizibilidades (como disse Michel Foucault). A voz, as trajetórias e as reminiscências destas pessoas se sobressaem, o que os tornam objeto do livro e questionam as políticas que vêm sendo tomadas nos últimos anos no país.

E neste ponto que cabe uma inflexão. A perspectiva de análise apresentada na obra considera desde o prefácio, passando pela apresentação e no texto final uma abordagem com a qual concordamos parcialmente. É notório que houve no país um golpe político que interrompeu, na administração do Estado, uma trajetória ascendente de reparação histórica e inserção popular que avançou do lugar social subalterno tradicional para uma maior participação econômica, logo também de ascensão social. Contudo, parece haver certa reificação dos governos do Partido dos Trabalhadores, considerando apenas esta ascensão popular, que é absolutamente relevante, mas não é determinante na transformação das estruturas sociais, de tal forma que, uma vez que foram mantidas as estruturas, quando não foi mais importante, tais estruturas apearam a presidenta Dilma do cargo, sem sequer ser provado, de maneira convincente, um crime de responsabilidade. Os textos ignoram a pactuação de classes proposta pelo partido, que manteve os privilégios da elite econômica, materializadas na hegemonia das grandes empreiteiras e no monopólio de ínfima quantidade de bancos e que, em última análise, acabou por levar a sua deposição. Fazendo com que as conquistas da classe trabalhadora e dos grupos subalternos, parecesse um "prêmio de consolação" àqueles que majoritariamente apoiaram os governos petistas, mas que, contraditoriamente, influenciados pela mídia elitista, acabaram por eleger o governo atual, que despreza tais grupos. À parte a divergência, a sensação de vilipêndio é predominante numa ou noutra abordagem do processo e a constatação de que engendramos uma fase de perdas sem precedentes para a formação de uma sociedade justa parece, a cada dia, mais evidente.

O texto inicial interpreta a obra do educador português António Nóvoa. Para Ana Cristina Souza, a abordagem de Nóvoa inova por pensar a construção do conhecimento e por dar destaque ao professor na análise do seu próprio ofício. Embora, pelo modo como a autora apresenta, pareça que o educador realize uma separação questionável entre a pessoa e o professor, há uma relação intelectual próxima entre Nóvoa e Paulo Freire no que tange a formação docente e seu papel relevante na validação da experiência do estudante como sujeito autônomo. 
O segundo e terceiro artigos evidenciam os problemas atuais de ataques aos Direitos Humanos dentro das escolas. A prática docente é o que os une: de um lado, Marta Rovai e João Pedro Oliveira apresentam propostas de atividades para a sala de aula com os temas de equidade de gênero e da violência contra a mulher; do outro, Fabrício Sampaio e Ivaldinete Gémes questionam a retórica conservadora e fascista da "ideologia de gênero" e seus efeitos no corpo docente de uma escola em Araioses/MA.

Outro texto é de Indaia Lopes, no qual é apresentada a aplicação do Programa Nacional de Alimentação escolar (PNAE) em Passo Fundo/RS. O texto é esclarecedor no que se refere à explicação dos detalhes do programa, que é, sem dúvida uma política pública garantidora de nutrição e combate à fome de significativa (se não a maior) parte das crianças brasileiras. Todavia, no cotejamento que a autora faz entre a aplicação do programa no estado (do RS) e do município, há um pêndulo deliberadamente favorável ao gestor municipal, acatando sem crítica o discurso de realização da gestão que é corroborado pelos dados da pesquisa, numa atitude que parece reforçar o discurso do político, contradizendo o método históricodialético que a própria autora advoga se apoiar.

O texto seguinte aborda as narrativas orais de antigos estudantes de um tradicional colégio de Parnaíba/PI, o Ginásio São Luiz Gonzaga. No estudo de Maria Dalva Cerqueira, fica explícito o desejo de “conhecer as representações construídas pelos entrevistados sobre as práticas educativas vivenciadas [...]" (p. 96). O método é o da História Oral e as memórias são evocadas como aspecto central para delinear a trajetória da instituição, que em nossa perspectiva parece ser o objetivo maior. Contudo, não parece ser esta uma intenção da autora, pois dá mais atenção aos relatos particulares dos antigos estudantes na sua relação com os professores (sacerdotes ou não) do que destes relatos com a formação da instituição. Também não se propõe a realizar uma crítica das práticas pedagógicas relatadas pelos interlocutores, o que nos pareceu uma falha.

Já Marcela Boni Evangelista apresenta uma excelente e necessária discussão sobre a história oral como campo de conhecimento e de sólida metodologia. Em uma abordagem em que apresenta os “interditos" no vão entre os ditos e não ditos dos interlocutores, a autora mostra domínio e cuidado no tema do direito ao aborto, e no valor da história oral para uma compreensão mais ampla do processo a partir dos sujeitos envolvidos. Em nosso entendimento, o texto mereceria uma revisão apenas no fechamento quando poderia alinhavar de modo mais nítido o trecho teórico-metodológico com a parte empírica, de análise específica de casos.

Os dois textos seguintes são biográficos e ambos relatam a vivência de mulheres em vilas de pescadores. No primeiro, Pedro Oliveira apresenta a história de Tereza e Adelaide, residentes da praia de Pedra do Sal, município de Parnaíba/PI, a partir de suas memórias no cotidiano desta localidade na década de 1970. A participação ativa delas e de outras mulheres na dinâmica da comunidade quebra a ideia comum 
de que a pesca é uma atividade de total responsabilidade masculina. $\mathrm{O}$ que nos provocou estranhamento foi o fato de os relatos serem iniciados com a perspectiva masculina, dos filhos e do primo, para só enfim "ouvirmos" as colaboradoras-protagonistas. O segundo, de autoria de Vitor Gama, disserta sobre as professoras em uma escola pública municipal na Vila de Pescadores de Picinguaba, em Ubatuba/SP. Apesar de quatro das cinco professoras entrevistadas não morarem na vila, elas contam o motivo de estarem ali e como foi o processo de adaptação entre elas e a comunidade caiçara, e vice e versa.

Por fim, encerra o livro um texto que faz uma leitura da história recente do país com a qual temos parcial concordância. Sobre as divergências de interpretação dos fatos já tratamos acima, mas caberia uma última consideração. Francisco Castro e Simone Sousa Silva poderiam ter "alinhavado" todos os textos sob sua perspectiva historiográfica e ideológica. A ausência deste fechamento deu a nítida sensação que faltou a obra uma supervisão orientadora dos textos. De modo que fica confirmada a sensação de que a reunião dos textos não teve um objetivo comum, salvo a de apresentar vivências microterritoriais que dão relevo ao cotidiano das pessoas comuns em uma variedade de lugares não centrais do território brasileiro. Cremos que é neste ponto que reside a força do livro, a noção de que a vida cotidiana das pessoas é o que forma e consolida a identidade do nosso povo. Se esta abordagem estivesse patente desde o início, a obra teria nisto sua maior força. 